\title{
Electrophoretic Deposition of Alumina on Conductive Polymer-Coated Ceramic Substrates
}

\author{
Tetsuo UCHIKOSHI, Seiichi FURUMI, Tohru S. SUZUKI and Yoshio SAKKA \\ Materials Engineering Laboratory, National Institute for Materials Science, 1-2-1, Sengen, Tsukuba-shi, Ibaraki 305-0047 \\ 導電性ポリマーを被覆したセラミックス基材へのアルミナの電気泳動堆積 \\ 打越哲郎·古海誓一・鈴木 達·目 義雄 \\ (独)物質・材料研究機構材料研究所, 305-0047 茨城県つくば市千現 1-2-1
}

\begin{abstract}
The coating of conductive polypyrrole (Ppy) on nonconductive ceramic substrates was performed by polymerization of pyrrole $(P y)$ in an aqueous solution. The Ppy film was characterized by scanning electron microscopy and conductivity measurements. Electrophoretic deposition of bimodal alumina suspension prepared with a phosphate ester was performed using Ppy film as a cathode. Fabrication of alumina ceramics with irregular shapes or complicated patterns were also attempted by sintering the deposits together with the Ppy coated substrates in air.

[Received September 21, 2005; Accepted October 20, 2005]
\end{abstract}

Key-words : Electrophoretic deposition, Electrode, Pyrrole, Polypyrrole, Alumina, Free-standing film

1. Introduction

Electrophoretic deposition (EPD) is a colloidal process wherein ceramic bodies are directly shaped from a stable colloidal suspension by a dc electric field. ${ }^{1)-3}$ Metals or graphite have been commonly used as substrates since electrically conductive materials must be used as the electrodes. Graphite electrodes, which can be burned out during sintering with deposits in air, are often used to fabricate free-standing films and thick ceramics with irregular shapes. ${ }^{4)-6)}$ However, the adhesion of deposits to the graphite surface is relatively weak because of its chemically inert property; it sometimes leads to the thick deposits peeling off or cracking during drying.

Recently, electrically conductive polymers such as polyaniline, polypyrrole and polythiophene have attracted much attention for use in electronic devices, electrochemical devices, functional electrodes, sensors and so on. ${ }^{7)}$ Conductive polymers can be prepared by chemical or electrochemical polymerization. ${ }^{7)}$ The advantages of chemical synthesis are cost effectiveness for mass production and easiness of the polymerization of monomers in the presence of oxidizing agents or catalysts.

Polypyrrole (Ppy) is one of the most extensively studied conductive polymers since the monomer, pyrrole $(\mathrm{Py})$, is commercially available, water soluble, easily oxidized, and moreover Ppy can be coated on various metal and ceramic surfaces. Ppy is expected to be a good electrode material for fabricating shape-designed ceramics by EPD processing since it shows high electric conductivity and burnability in air at $<500^{\circ} \mathrm{C}{ }^{8}{ }^{8}$ In this study, Ppy film was coated on non-conductive ceramic materials so that they can be used as the substrates for EPD.

\section{Experimental}

$0.01 \mathrm{M}$ ammonium peroxodisulfate $\left(\mathrm{NH}_{4}\right)_{2} \mathrm{~S}_{2} \mathrm{O}_{8}$, an oxidant, and $0.01 \mathrm{M} \mathrm{2,6-naphthalenedisulfonic} \mathrm{acid} \mathrm{disodium}$ salt $\mathrm{C}_{10} \mathrm{H}_{6}\left(\mathrm{SO}_{3} \mathrm{Na}\right)_{2}$, a doping agent, were dissolved in distilled water. The substrate materials, silane coated slide glasses $(26 \times 76 \mathrm{~mm})$ or small pieces of sintered alumina ceramics, were hung and soaked in the solution, and then $0.01 \mathrm{M}$ pyrrole $\mathrm{C}_{4} \mathrm{H}_{5} \mathrm{~N}$ were added via a syringe. The surfaces of the substrate

materials were covered with thin Ppy films produced by the polymerization of Py according to the following reaction;

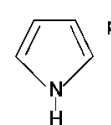

pyrrole

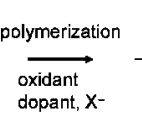

dopant, $\mathrm{X}$$$
\text { . }
$$

pyrrole polypyrrole
The polymerization was allowed to proceed for $15-18 \mathrm{~h}$ at $0^{\circ} \mathrm{C}$ or $25^{\circ} \mathrm{C}$.

The Ppy-coated substrates were dried at room temperature in air, and then powdery Ppy only lightly adhered to the Ppy film was brushed away. Electrical conductivity of the Ppy film was measured by using Ppy-coated slide glasses with the Keithley 2400 SourceMeter ${ }^{\circledR}$. The surface morphology and cross section of the Ppy film were observed by SEM (KEYENCE VE-8800 3D Real Surface View Microscope $\left.{ }^{\circledR}\right)$.

The electrophoretic deposition of alumina was carried out using a bimodal alumina suspension to enhance the green density. ${ }^{9)}$ A mixture of alumina powders with average particle sizes of $0.6 \mu \mathrm{m}$ (AKP-15, Sumitomo Chemical Co.) and 30 $\mathrm{nm}$ (NanoTek ${ }^{\circledR} \mathrm{Al}_{2} \mathrm{O}_{3}$, C.I Kasei Co., Ltd.) in a weight ratio of $9: 1$ was dispersed in ethanol, and a 7 vol $\%$ suspension was prepared. Figure 1 shows the relative green densities of the compacts as a function of the nanopowder content, determined by our preliminary experiments. The mixture of the submicron powder and the nano powder in the ratio of $9: 1$ shows the highest green density. Butoxyethyl acid phosphate (BAP), and poly vinyl butyral (PVB) were used as dispersant and binder, respectively. A pH meter (Model HM-14P, TOA Electronic, Ltd.) and an electric conductivity meter (Model ES-12, Horiba, Ltd.) were used to determine the appropriate addition of the BAP. It must be noted that the "operational $\mathrm{pH}$ ” measured using a $\mathrm{pH}$ meter calibrated for aqueous solvent differs from the real $p a_{\mathrm{H}}$ in a nonaqueous solvent; i.e., ${ }^{1), 10)}$

$$
p H-p a_{\mathrm{H}}=\frac{\Delta E j}{\left(\frac{R T \ln 10}{F}\right)}
$$


or

$$
p H-p a_{\mathrm{H}}=\frac{\Delta E j}{0.05916} \quad\left(\text { at } 25^{\circ} \mathrm{C}\right)
$$

where $p a_{\mathrm{H}}\left(=-\log a_{\mathrm{H}}\right)$ is the negative logarithm of the proton activity in a nonaqueous solvent, $\Delta E j$ is the residual liquidjunction potential encountered in the standardization and testing step of a standard $\mathrm{pH}$ meter. For the ethanol suspension, $(\Delta E j / 0.05916)=-1.23$ was calculated by Wang et al. ${ }^{10)}$ In this paper, the operational $\mathrm{pH}$ was used for convenience.

The EPD was carried out at a constant voltage of $50 \mathrm{~V}$ using a suspension prepared with 4.3 mass \% BAP and 1.1 mass $\%$ PVB. A stainless steel plate was used as an anodic counterelectrode. The relation of deposit weight versus time was examined by using Ppy-coated slide glass substrates. The deposit weight was measured by weighing the substrates before and after the deposition, followed by drying in air at room temperature. Similar EPD experiments were conducted using glass slides dip-coated with colloidal graphite (Aquadag, Ted Pella Inc.) for comparison. Ppy-coated irregular or pattern-impressed alumina substrates were also used to fabricate alumina ceramics by sintering the deposits together with the substrates in air.

\section{Results and discussion}

3.1 Characterization of the Ppy films

Figure 2 shows the typical surface and cross sectional

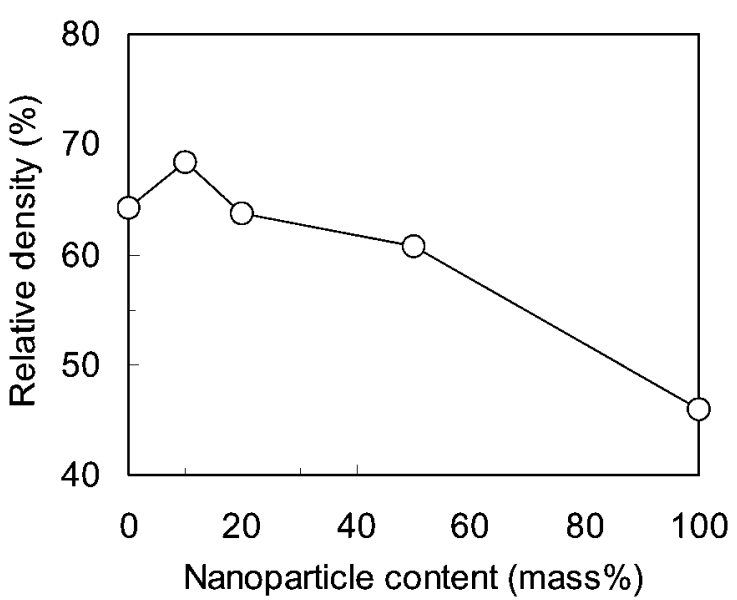

Fig. 1. Relative green densities of the bimodal alumina compacts. micrographs of the Ppy and graphite films prepared on the glass slide. The Ppy film has a somewhat bumpy surface, fairly uniform thickness and dense microstructure. The average thickness of the Ppy film determined by SEM observation was $\sim 0.5 \mu \mathrm{m}$. The graphite film has a rather porous and uneven surface microstructure. The average electric conductivities of the Ppy films polymerized at $25^{\circ} \mathrm{C}$ and $0{ }^{\circ} \mathrm{C}$, and the graphite film, were $0.60 \mathrm{~S} / \mathrm{cm}, 5.88 \mathrm{~S} / \mathrm{cm}$ and $3.85 \times 10^{2} \mathrm{~S} / \mathrm{cm}$, respectively. The electric conductivity of the Ppy film polymerized at $0^{\circ} \mathrm{C}$ was lower than that of the graphite film but superior to that of the Ppy film polymerized at $25^{\circ} \mathrm{C}$. The effect of low temperature synthesis on the preparation of Ppy with higher conductivity has been also reported elsewhere. ${ }^{8), 11)}$ Therefore, the Ppy films polymerized at $0^{\circ} \mathrm{C}$ were used as the cathodes for the following EPD experiments.

\subsection{Suspension preparation}

The operational $\mathrm{pH}$ and conductivity of the suspension as a function of weight ratio of BAP to the powder are shown in Fig. 3. As the amount of BAP increased, the $\mathrm{pH}$ dropped and the electrical conductivity increased. The butoxyethyl acid phosphate used in this study was a mixture of the mono- and di-phosphate esters, $\left(\mathrm{C}_{4} \mathrm{H}_{9} \mathrm{OC}_{2} \mathrm{H}_{4} \mathrm{O}\right)_{n} \mathrm{P}(\mathrm{O})(\mathrm{OH})_{3-n} n=1,2$. It dissociates in an organic solvent and liberates the protons (or hydronium ions) from the hydroxyl groups bonded to the phosphorus as follows.

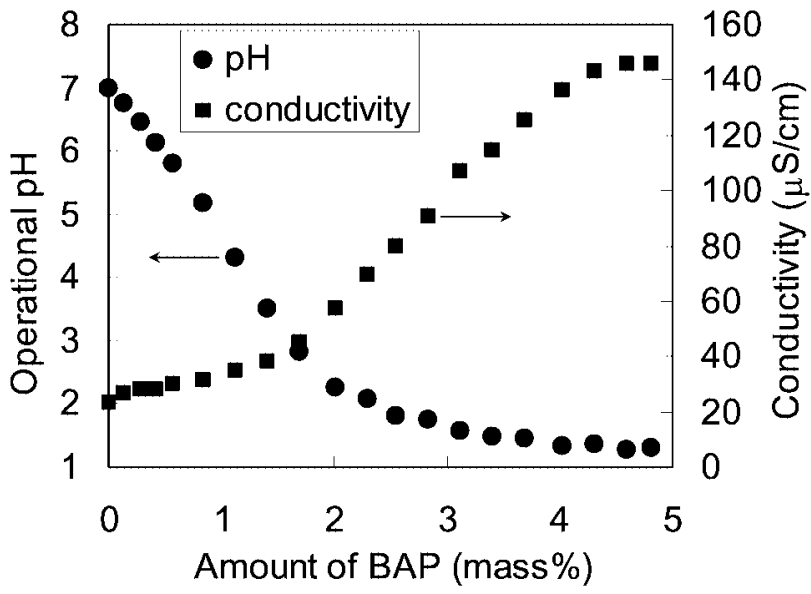

Fig. 3. Operational $\mathrm{pH}$ and conductivity of the suspension as a function of weight ratio of $\mathrm{BAP}$ to the $\mathrm{Al}_{2} \mathrm{O}_{3}$ powder.
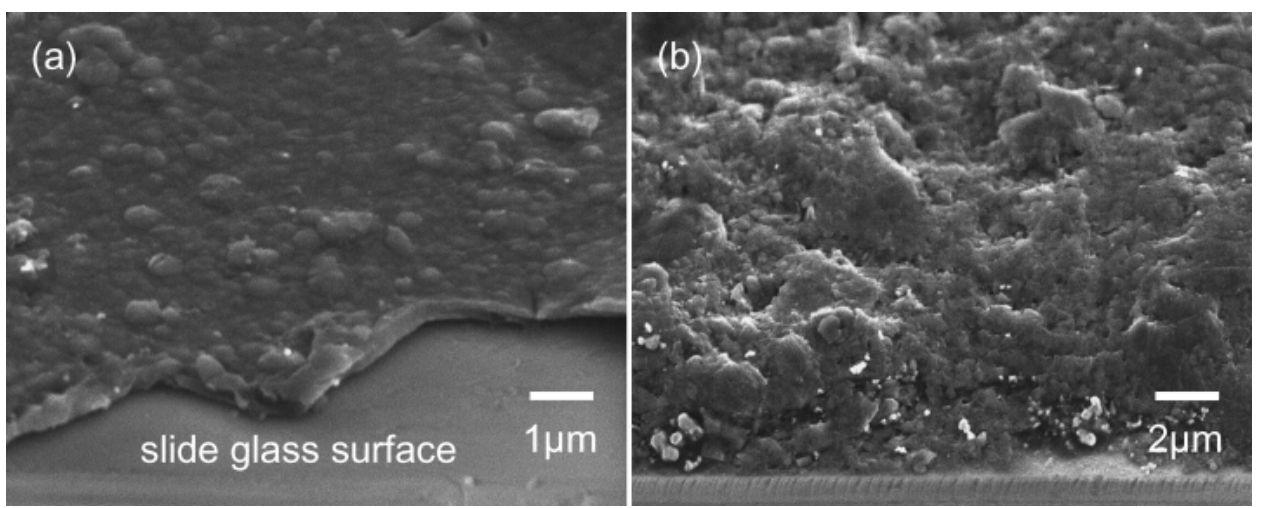

Fig. 2. Typical surface and cross sectional micrographs of the (a) Ppy and (b) graphite films prepared on slide glasses. 
<smiles></smiles>

monoester

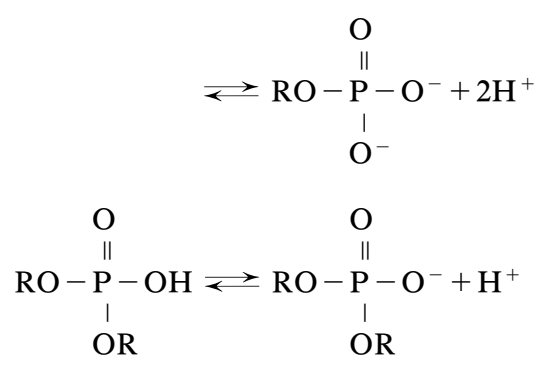

diester

The protons adsorb on the powder and make the powder surface positively-charged. When the amount of BAP is increased, the amount of adsorbed protons becomes gradually saturated and the dissociation of BAP reaches the equilibrium state. As a result, the dissociation of BAP stops and excess BAP molecules exist in the neutral state in the suspension. That is why the decrease in $\mathrm{pH}$ and the increase in the electric conductivity gradually show the gradual changes, as shown in Fig. 3. In our previous studies, the maximum zeta-potential was achieved with the BAP addition which shows the change in the slopes of the operational $\mathrm{pH}$ and conductivity versus the BAP addition. ${ }^{12)}$ Therefore, the suspension prepared with 4.3 mass \% BAP was considered to be appropriate.

3.3 EPD of $\mathrm{Al}_{2} \mathrm{O}_{3}$ suspension

Figure 4 shows the deposit weight of the alumina on the glass slides coated with Ppy or graphite as a function of time. The deposit thickness was determined from the SEM observations. The amount of deposit on the Ppy was almost consistent with that on the graphite though the electrical conductivity of the Ppy electrode was lower than that of the graphite electrode. It was confirmed that the graphite electrode can be completely replaced with the Ppy electrode for the EPD processing. It should be noted that in constant voltage deposition, the potential-induced electrophoresis decreases with increasing deposition on the electrode. This voltage drop across the electrodes results in the decrease in current density and, hence, the deposition rate. ${ }^{13)}$ Figure 5 shows a typical surface and cross sectional micrograph of alumina deposit. The adhesion of the alumina deposits to the Ppy surfaces was excellent. Thick, crack-less deposits with $>1 \mathrm{~mm}$ thickness could be obtained by EPD at $50 \mathrm{~V}$ for $4-5 \mathrm{~h}$. The green density of those thick deposits measured by Archimedes' method was $\sim 68 \%$ of the theoretical density. Figure 6 shows the microstructures of the as-deposited material with the thickness of $\sim 1 \mathrm{~mm}$. Most of the particles are submicron size on the substrate side, whereas the void spaces between the larger particles are filled with the nano particles at the outermost surface. The proportion of the coarse/fine particles in the deposit seems to be graded. This bimodal microstructure probably contributes to the high green density and effectively suppresses large shrinkage and cracking of the compacts during drying. The EPD at higher voltages of 100-300 V could speed up the deposition but caused the generation of 'warts' and vertical stripes on the deposit surface.

Finally, EPD was conducted using the Ppy-coated irregular alumina substrates. Figure 7 shows the procedure to fabricate alumina caps: (a) Ppy-coated alumina substrate, (b) EPDed green body, (c) and (d) sintered alumina cap. The outward

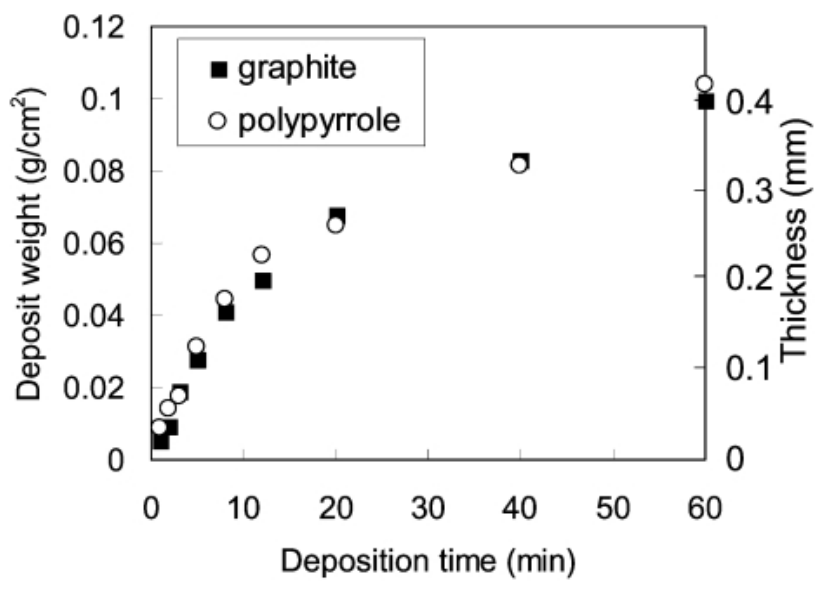

Fig. 4. Deposit weight of the alumina on the Ppy- or graphite-coated slide glass substrates as a function of time. The deposit thickness was determined from the SEM observations.

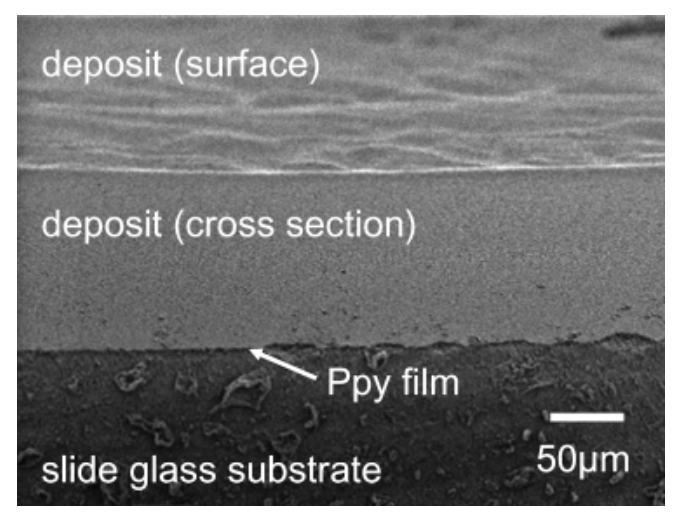

Fig. 5. Typical surface and cross sectional micrograph of the alumina deposits.

appearance of the substrate was well transcribed to the inside of the alumina cap. Figure 8 shows an alumina free-standing film with a rather complicated pattern from a coin: (a) the original pattern, (b) the pattern-impressed alumina substrate, (c) and (d) sintered alumina free-standing films with the transcribed pattern. In the above two cases, the sintering was conducted at $1100^{\circ} \mathrm{C}$ for $2 \mathrm{~h}$. This condition was optimal to detach the sintered alumina ceramics from the substrates without cracking. Alumina ceramics with complex shapes and patterns were successfully obtained by sintering the deposits together with the Ppy-coated substrate materials in air. This technique can be utilized for fabricating various shape-controlled ceramics by EPD.

\section{Conclusions}

The Ppy film had slightly rough surface, fairly uniform thickness and dense microstructure. The average thickness of the Ppy film was $\sim 0.5 \mu \mathrm{m}$. The average electric conductivities of the Ppy films polymerized at $25^{\circ} \mathrm{C}$ and $0^{\circ} \mathrm{C}$ were $0.60 \mathrm{~S} / \mathrm{cm}$ and $5.88 \mathrm{~S} / \mathrm{cm}$, respectively. The EPD characteristics of the Ppy-coated substrates were similar to that of graphite. Thick, crack-free deposits of alumina powder were formed on the Ppy-coated ceramic substrates by electrophoretic deposition (EPD). Adhesion of the deposits to the Ppy surfaces was fairly good. Alumina ceramics with irregular shapes or complex 

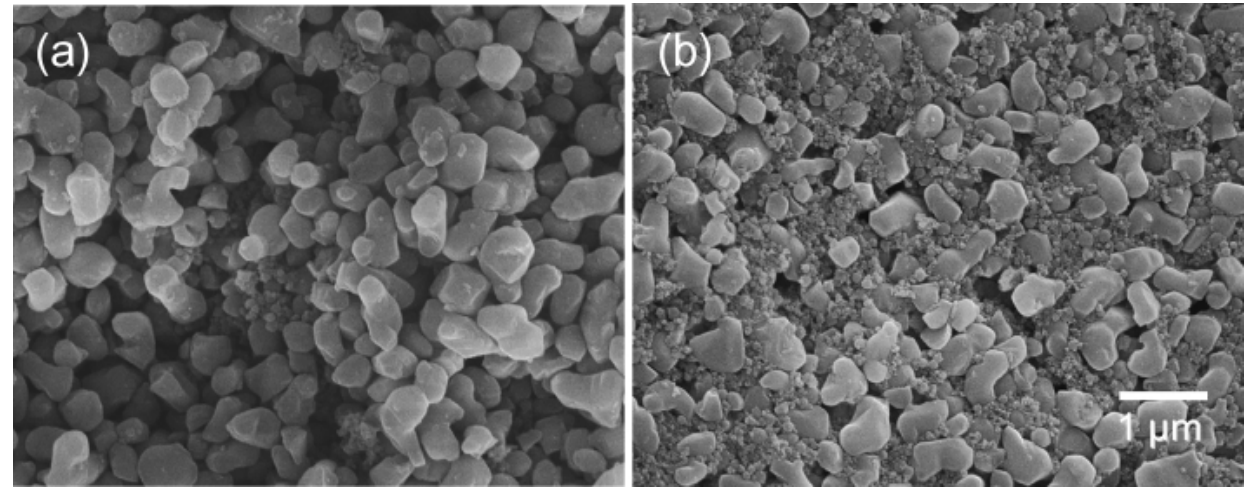

Fig. 6. SEM microstructures of the as-deposited alumina film with a thickness of $\sim 1 \mathrm{~mm}$ : (a) the substrate side, (b) the surface side.

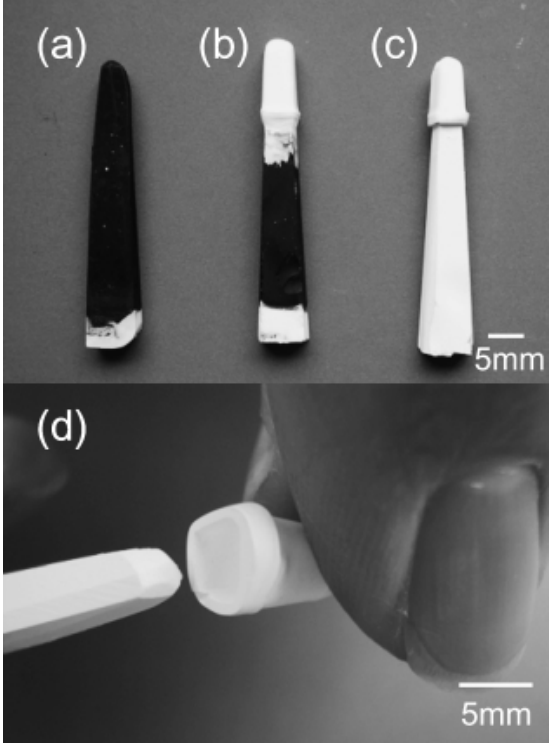

Fig. 7. Fabrication of alumina caps outside of irregular alumina substrates: (a) Ppy-coated alumina substrate, (b) EPDed green body, (c) and (d) Sintered alumina cap.

patterns were obtained by sintering the deposits together with the substrates in air.

Acknowledgments The authors wish to thank Ms. Ayako Miki of the National Institute for Materials Science for her assistance in the experiments and Mr. Koji Kuramoto of the Keyence Inc. for his SEM observations. This research was partially supported by the Budget for Nuclear Research of the Ministry of Education, Culture, Sports, Science and Technology (MEXT) and a Grant-in-Aid for Scientific Research (No. 15560593) from the MEXT.

\section{References}

1) Sarkar, P. and Nicholson, P. S., J. Am. Ceram. Soc., Vol. 79, pp. 1987-2002 (1996).

2) Zhitomirsky, I., Adv. Colloid \& Interface Sci., Vol. 97, pp. 279-317 (2002).

3) Boccaccini, A. R. and Zhitomirsky, I., Current Opinion in Solid State \& Mater. Sci., Vol. 6, pp. 251-260 (2002).
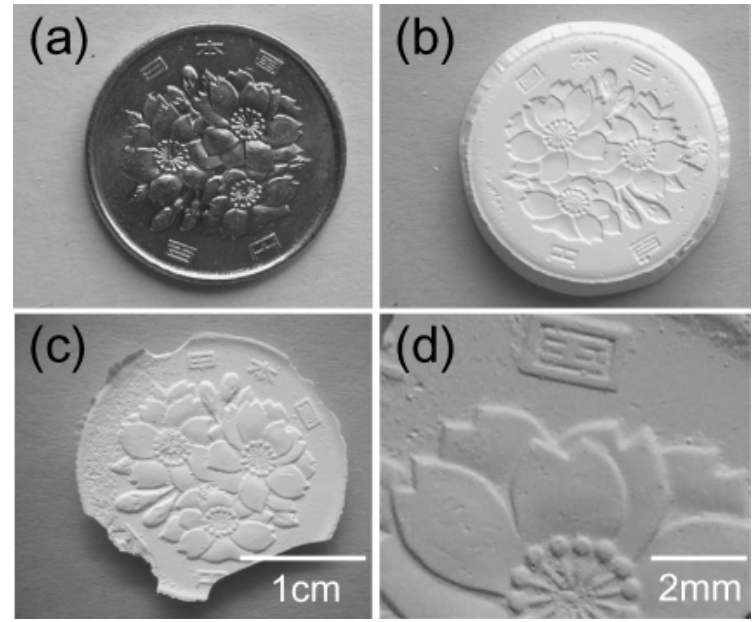

Fig. 8. Alumina free-standing film with complicated pattern: (a) Original pattern, (b) Pattern-impressed alumina substrate, (c) and (d) Sintered alumina free-standing film with the transcribed pattern.

4) Hayashi, S., Aoki, T. and Nakagawa, Z., J. Ceram. Soc. Japan, Vol. 113, pp. 513-518 (2005).

5) Ferrari, B., de Francisco, I. M. and Moreno, R., Ceram. Int., Vol. 31, pp. 863-868 (2005).

6) Negishi, H., Sakai, N., Yamaji, K., Horita, T. and Yokokawa, H., J. Electrochem. Soc., Vol. 147, pp. 1682-1687 (2000).

7) "New Applications of Conducting Polymers," Ed. by Kobayashi, Y., CMC, Tokyo (2004).

8) Bao, Y. and Nicholson, P. S., J. Am. Ceram Soc., Vol. 87, pp. 1767-1770 (2004).

9) Ravi, B. G., Chaim, R. and Gedanken, A., Nanostructured Materials, Vol. 11, pp. 853-859 (1999).

10) Wang, G., Sarkar, P. and Nicholson, P. S., J. Am. Ceram. Soc., Vol. 80, pp. 965-972 (1997).

11) Kassim, A., Basar, Z. B. and Mahmud, H. N. M. E., Proc. Indian Acd. Sci., Vol. 114, pp. 155-162 (2002).

12) Doungdaw, S., Uchikoshi, T., Noguchi, Y., Eamchotchawalit, C. and Sakka, Y., Sci. and Tech. Adv. Mater. (2005) in press.

13) Ma, J. and Cheng, W., Mater. Lett., Vol. 56, pp. 721-727 (2002). 